University of Nebraska - Lincoln

DigitalCommons@University of Nebraska - Lincoln

U.S. Department of Veterans Affairs Staff

Publications

U.S. Department of Veterans Affairs

1994

Haemophilus parainfluenzae Endocarditis: Application of a

Molecular Approach for Identification of Pathogenic Bacterial

Species

\author{
Kamal A. Hamed \\ Stanford University School of Medicine \\ Philip R. Dormitzer \\ Stanford University School of Medicine \\ Catherine K. Su \\ Stanford University School of Medicine \\ David A. Relman \\ Stanford University School of Medicine, relman@stanford.edu
}

Follow this and additional works at: https://digitalcommons.unl.edu/veterans

Hamed, Kamal A.; Dormitzer, Philip R.; Su, Catherine K.; and Relman, David A., "Haemophilus parainfluenzae Endocarditis: Application of a Molecular Approach for Identification of Pathogenic Bacterial Species" (1994). U.S. Department of Veterans Affairs Staff Publications. 2.

https://digitalcommons.unl.edu/veterans/2

This Article is brought to you for free and open access by the U.S. Department of Veterans Affairs at DigitalCommons@University of Nebraska - Lincoln. It has been accepted for inclusion in U.S. Department of Veterans Affairs Staff Publications by an authorized administrator of DigitalCommons@University of Nebraska - Lincoln. 


\title{
Haemophilus parainfluenzae Endocarditis: Application of a Molecular Approach for Identification of Pathogenic Bacterial Species
}

\author{
Kamal A. Hamed, Philip R. Dormitzer, Catherine K. Su, \\ and David A. Relman
} From the Division of Infectious Diseases and Geographic Medicine,
Department of Medicine, Stanford University School of Medicine,
Stanford; and the Department of Veterans Affairs Medical Center,
Palo Alto, California

\begin{abstract}
Haemophilus parainfluenzae is both a human oropharyngeal commensal bacterium and a cause of serious invasive disease. The fastidious growth characteristics of this organism and the poor specificity of traditional methods for species identification are likely to have led to inaccuracies in the diagnosis of infections caused by $H$. parainfluenzae and related organisms. We report a case of $\boldsymbol{H}$. parainfluenzae endocarditis in which confusion related to microbial identification was resolved by the analysis of $16 S$ ribosomal RNA sequences. Rapid identification was facilitated by amplification of $16 S$ ribosomal DNA directly from cultured cells with use of the polymerase chain reaction and by direct DNA sequence determination of the amplified product. This procedure is potentially useful for the identification of fastidious bacterial pathogens by reference laboratories.
\end{abstract}

Haemophilus parainfluenzae is a common inhabitant of the upper respiratory tract as well as an occasional pathogen. In one study, it was isolated from the throats of all of 10 healthy children and all of 10 healthy adults and constituted $74 \%$ of cultivated pharyngeal Haemophilus organisms [1]. Among Haemophilus species, this organism is the second most frequently isolated pathogen after Haemophilus influen$z a e$. Reported disease syndromes caused by $H$. parainfluen$z a e$ include endocarditis, meningitis, pharyngitis, epiglottitis, otitis media, dental abscess, conjunctivitis, brain abscess, pneumonia, empyema, septicemia, septic arthritis, osteomyelitis, soft-tissue abscess, peritonitis, hepatic abscess, and urinary tract infection $[2,3]$.

Endocarditis caused by Haemophilus species accounts for more than half of all cases caused by a group of fastidious coccobacillary organisms known as the HACEK group. The other organisms in this group are Actinobacillus actinomycetemcomitans, Cardiobacterium hominis, Eikenella corrodens, and Kingella kingae. HACEK organisms, in turn, cause more than half of all cases of gram-negative bacterial endocarditis [4]. It is likely that many cases of endocarditis caused by these organisms have been classified as culture-negative or attributed to the wrong species because of difficulties in iso-

Received 5 November 1993; revised 18 April 1994.

Financial support: Lucille P. Markey Charitable Trust (to D.A.R., a Lucille P. Markey Biomedical Scholar); Stanford PMGM Director's Research Fund, sponsored by SmithKline Beecham (to D.A.R.); and Stanford Department of Microbiology and Immunology National Research Service Award T32-AI07328 (to P.R.D.).

Reprints or correspondence: Dr. David A. Relman, Palo Alto Veterans Affairs Medical Center, 154T, 3801 Miranda Avenue, Palo Alto, California 94304.

Clinical Infectious Diseases 1994;19:677-83

(C) 1994 by The University of Chicago. All rights reserved.

1058-4838/94/1904-0006\$02.00 lation or identification, especially of Haemophilus paraphrophilus and $H$. parainfluenzae. These organisms remain difficult to cultivate in the laboratory and usually require at least 1 week for identification to the species level. Their identification has been based on metabolic or biochemical features that may be variable or nonspecific [5].

Species and, in some instances, strains can be reliably identified by the analysis of certain specific gene sequences -in particular, those of the ribosomal RNA (rRNA) genes. This type of approach has been applied clinically to the identification of "unculturable" microbial pathogens and fastidious microorganisms such as the mycobacteria [6-9]. In this paper, we use a case of endocarditis to illustrate how a $16 \mathrm{~S}$ rRNA-based approach can be used to expeditiously resolve confusion regarding the identification of $H$. parainfluenzae.

\section{Materials and Methods}

Determination of $16 S$ rRNA sequence. A partial sequence of the $16 S$ rRNA gene of the bacterial isolate-referred to as UNK-from the case described below was obtained as follows. The bacterial cell mass from several minute colonies of a blood-bottle subculture was digested overnight at $55^{\circ} \mathrm{C}$ in $10 \mathrm{~m} M$ Tris-HCl (pH 7.5), $1 \mathrm{~m} M$ EDTA, $1 \%$ Laureth-12 (Mazer Chemicals, Gurnee, IL), and $0.2 \mathrm{mg}$ of proteinase $\mathrm{K} / \mathrm{mL}$ (Boehringer Mannheim, Indianapolis), as previously described [6]. After inactivation of the proteinase $\mathrm{K}$ at $94^{\circ} \mathrm{C}$ for 10 minutes, DNA from $1-\mu \mathrm{L}$ and $10-\mu l$ aliquots of the lysate was amplified by the polymerase chain reaction (PCR) with use of the bacterial broad-range $16 S$ rRNA primers 8FPL and 806R [10, 11]. The PCR products were separated by agarose gel electrophoresis and purified with the Magic PCR Preps System (Promega Corporation, Madison, WI). The purified DNA fragments were directly sequenced with the Taq polymerase-based $\mathrm{fmol}$ sequencing system (Pro- 
mega). The sequencing primers 50F (5'AACACATGCAAGTCGAACG $3^{\prime}$ ) and 512R ( $5^{\prime}$ CGAATTCCCGCGGCTGCTGGCACGGA3') were based on conserved bacterial $16 \mathrm{~S}$ rRNA sequences [11, 12]. The sequencing reactions were chased with terminal deoxynucleotidyltransferase (Gibco BRL, Gaithersburg, MD), and ${ }^{35}$ S-labeled sequencing products were analyzed by separation on buffer gradient polyacrylamide-urea gels and autoradiography [13].

Multiple-sequence alignment was performed with Pileup, a program in the Genetics Computer Group Sequence Analysis Software Package, version 7.1.1 [14]. Pileup uses a simplification of the progressive alignment method to create alignments and a dendrogram [15]. The sequences of $16 S$ rRNA genes from members of the family Pasteurellaceae, including a representative of each subcluster defined by Dewhirst et al. [16], and from Escherichia coli were obtained from GenBank (Bethesda, MD) and used as a data set for the alignment. The species of origin for these sequences (as listed by Dewhirst et al. [16]), the strain designations, and the GenBank accession numbers are as follows: $A$. actinomycetemcomitans, ATCC 29522, M75036; H. aphrophilus, ATCC 33389 ${ }^{\mathrm{T}}$, M75041; H. influenzae, ATCC 33391, M35019 and M59433; Actinobacillus seminis, ATCC $15768^{\mathrm{T}}$, M75047; Pasteurella species, CCUG 18782, M75055; Pasteurella multocida, NCTC 10322, M35018 and M59769; Haemophilus parasuis, NCTC $4557^{\mathrm{T}}$, M75065; Actinobacillus suis, ATCC 15557 , M75071; Actinobacillus ureae (listed by Gen Bank as Pasteurella ureae), Henrikson 3520/59 , M75075; Actinobacillus species (listed by GenBank as Actinobacillus capsulatus), CCUG 19799, M75067; Actinobacillus pleuropneumoniae, ATCC $27088^{\mathrm{T}}$, M75074; Haemophilus paraphrohaemolyticus, NCTC 10670, M75076; Haemophilus ducreyi, ATCC 33922, M75079; Pasteurella haemolytica, NCTC $9380^{\mathrm{T}}$, M75080; $H$. parainfluenzae, ATCC $33392^{\mathrm{T}}, \mathrm{M} 75081 ; H$. parainfluenzae (listed by GenBank as $H$. paraphrophilus), ATCC 29242, M75082; Haemophilus species, strain 202, M75077; Pasteurella pneumotropica, NCTC 8141 ${ }^{\mathrm{T}}$, M75083; and E. coli, K-12/MG1655, J01695. Base positions were identified by the numbering established for $E$. coli $16 S$ rRNA [17]. In order to ensure unambiguous alignment, bases 94-489 of each sequence were used for analysis.

The entire procedure-from cell digestion to sequence analysis-consumed $\sim 48$ hours; however, this procedure can be significantly shortened, as will be described below.

\section{Case Report}

A 24-year-old woman with nontropical sprue was admitted to Stanford University Medical Center with a 10-day history of nausea, emesis, and headache and a 4-day history of fever. She had no history of abdominal pain, diarrhea, photophobia, neck stiffness, or head trauma. The day before admission the patient had undergone a neurological examination that yielded normal results. A lumbar puncture at that time yielded CSF containing 6 red blood cells $/ \mathrm{mm}^{3}$, 9 leukocytes $/ \mathrm{mm}^{3}$ ( $100 \%$ monocytes), $27 \mathrm{mg}$ of protein $/ \mathrm{dL}$, and 58 $\mathrm{mg}$ of glucose/dL; the blood glucose level was $85 \mathrm{mg} / \mathrm{dL}$. Gram staining of the CSF revealed no organisms.

On admission the patient was lethargic and somewhat confused; her temperature was $39^{\circ} \mathrm{C}$, her blood pressure was $100 / 68 \mathrm{~mm} \mathrm{Hg}$, and her pulse was $108 / \mathrm{min}$, with orthostatic changes. Her fundi were unremarkable and her neck was supple. Examination of her mouth revealed good dental hygiene with multiple erupting wisdom teeth. A grade 1/6 systolic murmur was heard by one examiner. The lungs were clear to auscultation and percussion. Hepatosplenomegaly was detected. The patient was oriented to time, place, and person, and she had no focal neurological findings. The rest of the results of her physical examination were normal.

Initial laboratory findings included a peripheral-blood leukocyte count of $17,000 / \mathrm{mm}^{3}$, with $65 \%$ polymorphonuclear cells and 22\% band forms; a hematocrit of $32.0 \%$; a platelet count of $84,000 / \mathrm{mm}^{3}$; and the following serum levels: sodium, $135 \mathrm{mmol} / \mathrm{L}$; potassium, $2.7 \mathrm{mmol} / \mathrm{L}$; chloride, 95 $\mathrm{mEq} / \mathrm{L}$; bicarbonate, $30 \mathrm{mEq} / \mathrm{L}$; albumin, $2.7 \mathrm{~g} / \mathrm{dL}$; and lactate dehydrogenase, $952 \mathrm{IU} / \mathrm{L}$. Serum levels of creatinine, alkaline phosphatase, aspartate aminotransferase, and alanine aminotransferase were within normal limits. Urinalysis revealed microscopic hematuria. A chest roentgenogram was normal. Blood was drawn for cultures, and therapy was begun with parenteral broad-spectrum antibiotics.

On the second day of hospitalization, the patient developed photophobia, increased lethargy, and disorientation to time. She also had meningismus but exhibited no other neurological abnormalities. A second lumbar puncture documented a total CSF leukocyte count of $9 / \mathrm{mm}^{3}$, with $61 \%$ polymorphonuclear cells, $14 \%$ lymphocytes, and $25 \%$ monocytes. No red blood cells were detected in CSF; the protein level was $24 \mathrm{mg} / \mathrm{dL}$ and the glucose level was $50 \mathrm{mg} / \mathrm{dL}$. The glucose concentration in blood was $136 \mathrm{mg} / \mathrm{dL}$. The initial diagnosis was meningoencephalitis of probable viral origin, and intravenous acyclovir was added to the regimen. However, magnetic resonance imaging of the head revealed hyperintense areas that did not display enhancement with gadolinium in the left basal ganglia and the left middle cerebellar peduncle on a T2-weighted image. Transesophageal echocardiography performed on the same day showed mitral valve prolapse, a large vegetation on the anterior mitral leaflet, and possible posterior mitral annular abscess. By this time the systolic murmur heard on admission had increased to grade $3 / 6$, with radiation to the axilla.

On the fifth day of hospitalization, one of the cultures of blood drawn at admission became positive for small gramnegative rods with positive catalase but negative oxidase reactions. These organisms were preliminarily identified as $A$. (Haemophilus) actinomycetemcomitans. At this time two transient Janeway lesions were described on the palmar aspect of the fingers. The patient continued to be lethargic 


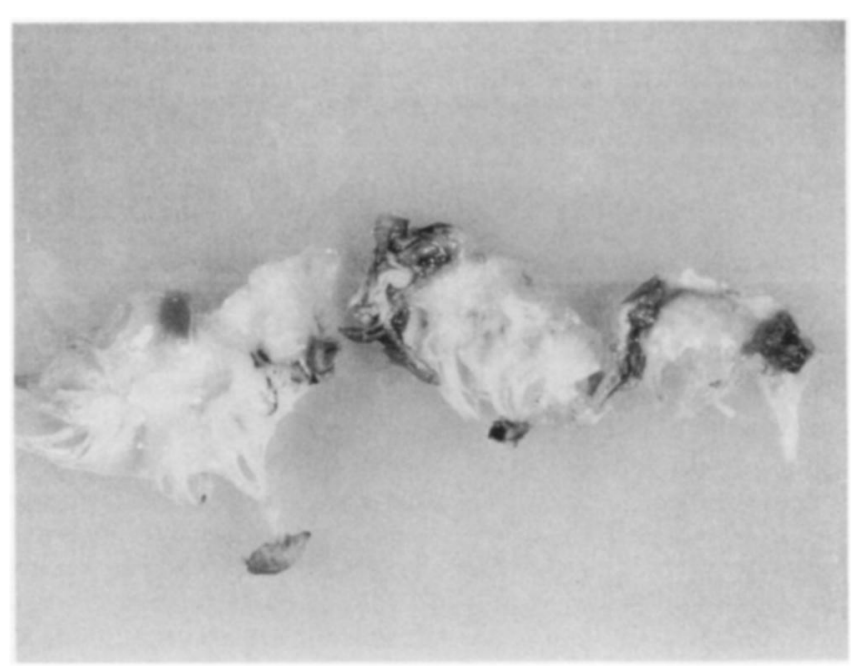

Figure 1. Mitral-valve leaflet vegetations from a woman subsequently shown to have Haemophilus parainfluenzae endocarditis. Small gram-negative bacilli were found within these vegetations (courtesy of Dr. Donald Regula, Department of Pathology, Stanford University School of Medicine).

and to have high-grade fever, but she had neither clinical evidence of congestive heart failure nor electrocardiographic evidence of conduction defects. On the sixth day of hospitalization, there was an abrupt onset of intense left-upper-quadrant abdominal pain. A computerized tomogram of the abdomen with contrast showed multiple low-density regions throughout the spleen-the largest measuring $4 \mathrm{~cm} \times 5 \mathrm{~cm}$ - that were consistent with infarctions. The scan also revealed hepatosplenomegaly. The following day the patient underwent mitral valve replacement with a bileaflet mechanical prosthetic valve. Loosely attached vegetations $2-7 \mathrm{~mm}$ in diameter were found on both leaflets of the native valve (figure 1). Microscopic examination of the valvular material revealed numerous small gram-negative bacilli.

The patient's postoperative course was generally uneventful, with resolution of fever on the second day. No CSF cultures yielded growth. The patient received intravenous ampicillin ( $12 \mathrm{~g}$ daily) for 3 weeks; because of the development of an ampicillin-associated rash, this drug was subsequently replaced with intravenous ceftriaxone ( $2 \mathrm{~g}$ daily), which was administered for an additional 3 weeks. In addition, intravenous gentamicin ( $2 \mathrm{mg} / \mathrm{kg}$ daily) was given for a total of 4 weeks. The patient was doing well 4 months after the initial episode.

An identical organism was eventually isolated from four of eight paired sets of blood cultures. Growth was detected in the aerobic bottle of each set 48-96 hours after inoculation as well as in one anaerobic bottle that was subcultured after 7 days. A Bactec 9240 system (Becton-Dickinson, Sparks, MD) was used with enriched soybean-casein digest broth bottles (BACTEC PLUS Aerobic/F and BACTEC Standard
Anaerobic/F). After 24 hours, pinpoint colonies were observed on chocolate agar plates only; gram staining revealed thin, delicate gram-negative rods. After 48 hours, these colonies became gray; in addition, fine pinpoint colonies were observed on Brucella agar plates. An oxidase test based on commercial tetramethylphenylenediamine reagent (BBL, Cockeysville, MD) was negative. The star-like colonial morphology and puff-like growth on the side of a brain-heart infusion broth tube that are sometimes seen with A. actinomycetemcomitans were not observed. Repeat oxidase testing of subcultured colonies gave a positive result. The organism required V Factor but not X Factor and was catalase-positive. It was subsequently identified as $H$. parainfluenzae biotype II, both by the RapID NH System (Innovative Diagnostic Systems, Atlanta) and by biochemical testing recommended by the Centers for Disease Control and Prevention (CDC). (However, the isolate did not ferment glucose and sucrose, probably because of poor growth.) The organism did not produce $\beta$-lactamase. The MICs for the strain were as follows: ampicillin, $0.25 \mu \mathrm{g} / \mathrm{mL}$; ceftriaxone, $\leqslant 0.015 \mu \mathrm{g} /$ $\mathrm{mL}$; and chloramphenicol, $\leqslant 0.5 \mu \mathrm{g} / \mathrm{mL}$. This isolate was studied in further detail, as described under Results.

\section{Results}

I6S rRNA sequence determination. The bacterial blood isolate (UNK) cultured from the case just described was initially identified by the clinical microbiology laboratory as an oxidase-negative strain of $A$. actinomycetemcomitans and was subsequently reclassified as an oxidase-positive strain of $H$. parainfluenzae. To resolve this discrepancy, we sought to identify the isolate by sequence analysis. A sequence comprising 411 base pairs of the bacterial $16 S$ rRNA gene (E. coli $16 S$ rRNA positions 79-489) was determined unambiguously for UNK (figure 2). This sequence was deposited in the Genome Sequence DataBase (Los Alamos National Laboratory, Los Alamos, NM) under accession number L26363. $16 S$ rRNA gene sequences from positions $94-489$ were available for all members of a sequence data set drawn from $E$. coli and from representative members of the Pasteurellaceae (listed in Materials and Methods) and could be aligned unambiguously with the UNK sequence. In a phylogenetic tree constructed with this alignment, the UNK sequence and the only two available $H$. parainfluenzae $16 S$ rRNA sequences formed a coherent, monophyletic lineage that was distinct from all other taxon lineages (data not shown). The UNK sequence was $99.2 \%$ identical to the sequence from one strain of $H$. parainfluenzae (GenBank accession number, $\mathrm{M} 75082$ ) and was $98.7 \%$ identical to the sequence from the second strain (M75081). The two published $H$. parainfluenzae sequences were $99.5 \%$ identical to each other in this region. The $16 S$ rRNA gene sequence from $H$. aphrophilus (M75041) was the next most closely related to the UNK 

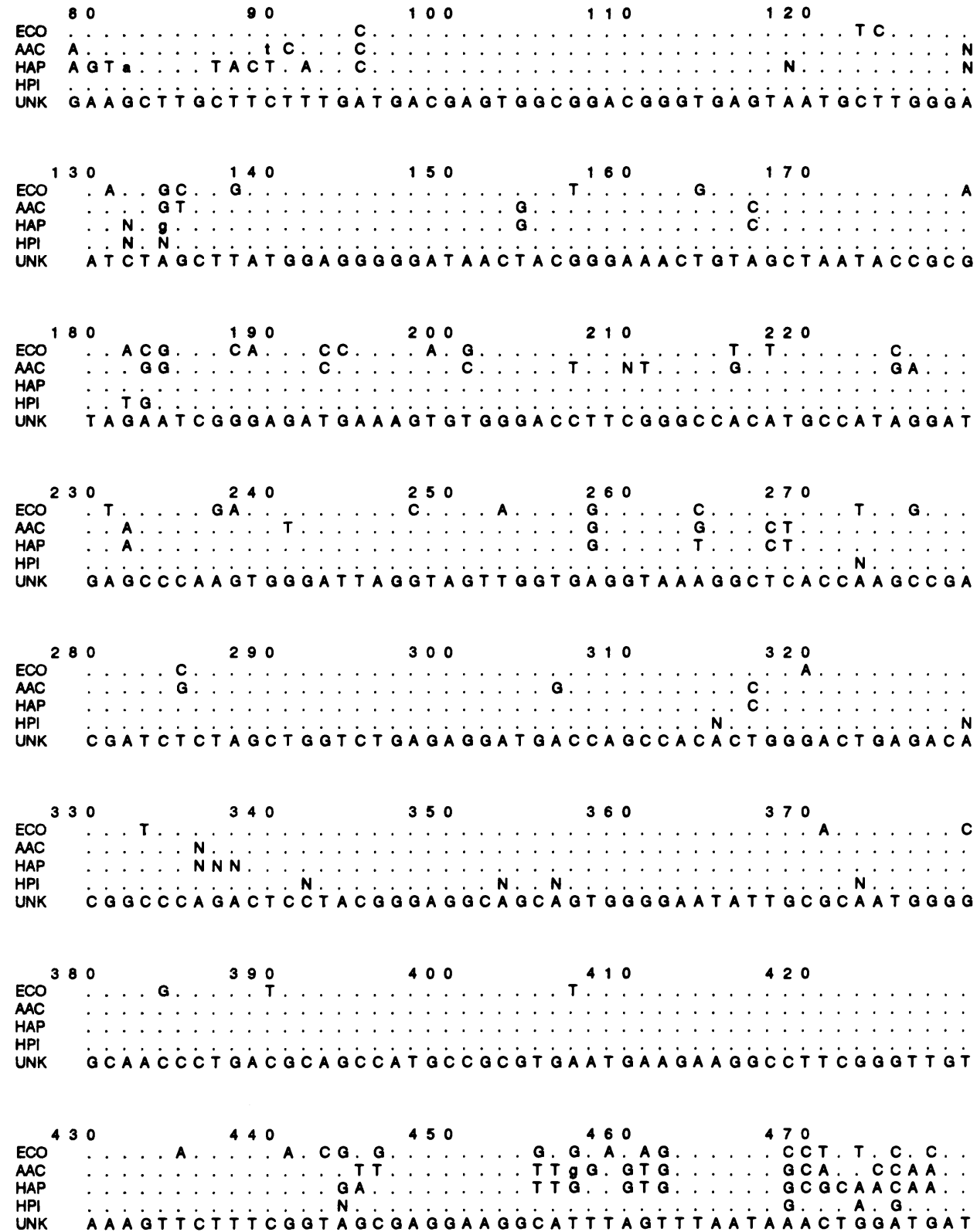

Figure 2. Sequences of $16 S$ rRNA genes from UNK (the bacterial blood isolate from a woman subsequently shown to have $\mathrm{Hae}$ mophilus parainfluenzae endocarditis), Escherichia coli, and selected members of the Pasteurellaceae. Positions 79-489 are shown, numbered according to the system for $E$. coli . The International Union of Biochemistry nucleotide code is employed, with lower-case letters denoting ambiguous nucleotides in published sequences, $N$ s denoting undetermined bases, and dots denoting identity with the UNK sequence. $E C O$ denotes $E$. coli (GenBank accession number, J01695); $A A C$, Actinobacillus actinomycetemcomitans (M75036); HAP, Haemophlus aphrophilus (M75041); and HPI, H. parainfluenzae (M75081). The UNK partial $16 S$ rRNA sequence has been deposited in the Genome Sequence DataBase (accession number, L26363).

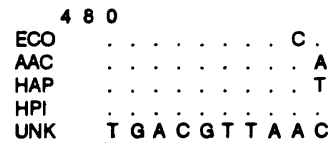

sequence, with $92.9 \%$ identity. The sequence from $A$. actinomycetemcomitans (M75036) was $89.9 \%$ identical to the UNK sequence.

Three nucleotide differences between the UNK sequence and either or both of the $H$. parainfluenzae sequences occurred at non-base-paired positions (numbered 182, 183, and 469 ) of $16 S$ rRNA. The two other nucleotide differences between the UNK sequence and both $H$. parainfluenzae sequences occurred at base-paired positions within established
$16 S$ rRNA secondary structures [18]. The latter substitutions preserve canonical and noncanonical base pairing within these structures (position 473, A-U $\rightarrow$ G-U; position 475 , G-U $\rightarrow$ A-U). Selected comparisons with use of more complete $16 S$ rRNA gene sequences $(1,483$ and 1,479 bases in length) from the $H$. parainfluenzae strains indicate that the region from position 94 to position 489 shows more variability than does the more complete sequence (data not shown). Since $16 S$ rRNA sequences from different species generally 
Table 1. Characteristics differentiating HACEK organisms.

\begin{tabular}{|c|c|c|c|c|c|c|c|c|c|c|c|}
\hline \multirow[b]{3}{*}{ Organism } & \multirow{2}{*}{\multicolumn{2}{|c|}{$\begin{array}{l}\text { Factor } \\
\text { required } \\
\text { for } \\
\text { growth }\end{array}$}} & \multicolumn{6}{|c|}{ Expression or biochemical activity of indicated enzyme } & \multirow{2}{*}{\multicolumn{3}{|c|}{ Production of acid from }} \\
\hline & & & \multirow{2}{*}{$\begin{array}{l}\text { Indole } \\
\text { production }\end{array}$} & \multirow[b]{2}{*}{ Urease } & \multirow[b]{2}{*}{ Oxidase } & \multirow[b]{2}{*}{ Catalase } & \multirow[b]{2}{*}{$\begin{array}{c}\text { Lysine } \\
\text { decarboxylase }\end{array}$} & \multirow[b]{2}{*}{$\begin{array}{l}\text { Nitrate } \\
\text { reduction }\end{array}$} & & & \\
\hline & $\mathrm{X}$ & $\mathrm{V}$ & & & & & & & Glucose & Lactose & Sucrose \\
\hline \multicolumn{12}{|l|}{ Haemophilus } \\
\hline \multicolumn{12}{|l|}{ Haemophilus } \\
\hline paraphrophilus & - & + & - & - & + & - & - & + & + & + & + \\
\hline \multicolumn{12}{|l|}{ Haemophilus } \\
\hline aphrophilus & $+^{*}$ & - & - & - & $\mathrm{V}$ & - & - & + & + & + & + \\
\hline \multicolumn{12}{|l|}{ Actinobacillus } \\
\hline actinomycetemcomitans & - & - & - & - & V & + & - & + & + & - & - \\
\hline \multicolumn{12}{|l|}{ Eikenella } \\
\hline \multicolumn{12}{|l|}{ Kingella } \\
\hline kingae & - & - & - & - & + & - & - & - & + & + & - \\
\hline
\end{tabular}

NOTE. Key: $+=$ more than $90 \%$ of strains positive; $-=$ more than $90 \%$ of strains negative; $\mathrm{V}=10 \%-90 \%$ of strains positive.

* Requirement for Factor $\mathrm{X}$ is reported at initial isolation but is lost on subculture.

differ by $>1.5 \%$ [19], our similarity scores as well as our dendrogram are consistent with the placement of UNK within the species boundaries for $H$. parainfluenzae.

\section{Discussion}

Russell and Fildes [20] first reported human disease due to $H$. parainfluenzae in 1928, some 6 years after the description of the species by Rivers [21]. H. parainfluenzae is a fastidious organism whose isolation often requires a long incubation period, specialized media, or terminal subculture. Colonies of $H$. parainfluenzae may grow to $3 \mathrm{~mm}$ in diameter after incubation at $35^{\circ} \mathrm{C}-37^{\circ} \mathrm{C}$ for 24 hours and may appear either flat, grayish, translucent, and smooth or rough and wrinkled. Gram staining may reveal pleomorphic gram-negative bacilli. In the identification of $H$. parainfluenzae, a requirement for Factor $\mathrm{V}$ should be established by the documentation of satellite growth around nicotinamide adenine dinucleotide-containing disks on nutritionally deficient medium, and the lack of a requirement for Factor $\mathrm{X}$ should be established by the porphyrin test, with $\delta$-aminolevulinic acid as substrate. Many clinical laboratories report all strains that require only Factor $\mathrm{V}$ as $H$. parainfluenzae. Thus, it is possible that the true prevalence of infection with this organism has never been established and that many cases reported as due to $H$. parainfluenzae may in fact be caused by other species that require only Factor V, such as $H$. paraphrophilus. Confirmation of species identity is sought only in certain circumstances by most laboratories and is based on growth- factor requirements, enzymatic activities, and fermentation patterns (table 1). These tests often require 10-14 days and may give misleading or variable results, depending on the degree of bacterial laboratory passage (e.g., the dependence of $H$. aphrophilus on Factor X [22]), the growth stage of the organism (a point particularly relevant to microorganisms that are difficult to cultivate in the laboratory), the manner in which the test is performed (e.g., the oxidase assay in the case we have reported herein), and naturally occurring differences among strains. Several commercial kits are available for relatively rapid identification of Neisseria species, Haemophilus species, and Moraxella catarrhalis (e.g., the HNID, API NH, and RapID NH systems) [23, 24]; however, additional tests are sometimes needed for the identification of $H$. parainfluenzae, other Actinobacillus species have not been adequately evaluated, and misidentifications do occur.

We reviewed the medical literature from 1966 to July 1993 and found 37 reports describing 73 cases of $H$. parainfluenzae endocarditis [25-30]. (A complete list of references is available from the authors upon request.) The mean duration of incubation of primary blood cultures until the detection of microbiological growth (reported in 54 cases) was 6.6 days, with a range of 1 day to 21 days. The interval from the detection of microbiological growth in liquid media to the identification of $H$. parainfluenzae was not stated in most instances but was as long as 12 days in one case report [31]. In 48 of the 73 cases, the method used for identification to the species level was given. In 11 cases, species identification was described only in terms of requirements for Factors $\mathrm{X}$ 
and $\mathrm{V}$; the results of hemolysis assessment were also included in two of these cases. Both growth-factor requirements and biochemical activities (as outlined in table 1) were reported in 37 cases. In 10 of these cases, the identity of $H$. parainfluenzae was confirmed by the CDC.

The identification of fastidious microbial pathogens in general is a problem of potentially wide magnitude. Even if a fastidious microorganism can be reliably propagated in the laboratory, microbial phenotypic characteristics are often variable and therefore unreliable for species identification; in addition, their determination may require lengthy periods. The identification of $H$. parainfluenzae by traditional methods illustrates these points. Many of the phenotypic characteristics used to distinguish among Haemophilus species and other HACEK organisms can vary among strains of the same purported species (table 1), in part because assay methods are poorly standardized. In addition, these phenotypes probably do not provide a means for unified and unambiguous classification of members of the family Pasteurellaceae [16].

Small-subunit (16S) rRNA sequence analysis may prove a rapid and specific approach to the identification of fastidious microorganisms. These sequences can be amplified directly from infected host tissue-with consequent elimination of the need for laboratory cultivation - and from minute quantities of culture material $[6,10]$. Small-subunit rRNA sequences currently form the basis for a revised approach to microbial taxonomy [11] and have been used to establish phylogenetic relationships among many bacteria, including members of the genus Mycobacterium [9, 32, 33], members of the family Pasteurellaceae [16, 34], and several previously uncharacterized human pathogens [6-8]. Analyses of the Pasteurellaceae have demonstrated four major clusters of strains, three of which correspond approximately to the genera Haemophilus, Actinobacillus, and Pasteurella. However, some members of each genus appear to have been erroneously classified by traditional methods. For example, $A$. $a c$ tinomycetemcomitans should probably be reclassified as a species of Haemophilus [16]. Conversely, members of the species $H$. parainfluenzae, which seems to include genetically heterogeneous strains, are more closely related to Actinoba cillus than to Haemophilus. Some strains of $H$. parainfluenzae may have been originally misidentified-e.g., as $H$. paraphrophilus-and vice versa. More recent $16 S$ rRNA-based analysis suggests that $H$. parainfluenzae may consist of a monophyletic cluster distinct from other known related organisms [34].

We analyzed a partial $16 S$ rRNA sequence from a cultivated bacterial pathogen purported to be $H$. parainfluenzae in order to clarify ambiguities about its identity and to demonstrate the potential usefulness of this approach for the identification of fastidious microorganisms to the species level. The region of the $16 S$ rRNA gene that we analyzed is one of the most variable for members of the Pasteurellaceae and is sufficient to reproduce the basic phylogenetic relation- ships among this group of organisms (data not shown). On the other hand, this region would not be adequate for the phylogenetic analysis of all clinical bacterial isolates. The UNK sequence is more closely related to the two available $16 S$ rRNA sequences for $H$. parainfluenzae than to any other sequences; it differs from each of the former two sequences at fewer than $1.5 \%$ of positions. A phylogenetic tree places these three strains of $H$. parainfluenzae in a monophyletic group that is distinct from other species. Thus, our data demonstrate convincingly that the clinical isolate UNK belongs within the species $H$. parainfluenzae. The minor sequence heterogeneity that we observed may indicate strain-related differences [9] or differences among the multiple copies of the rRNA operon in some organisms [35].

Although our procedure-from cell digestion to sequence analysis-consumed $\sim 48$ hours, it could easily have been shortened. Specifically, the time required for cell digestion could have been reduced to 1 hour, and one of the automated DNA-sequencing systems, which permit much more rapid collection of data [36,37], could have been used. With these modifications, the total time required for species identification might be reduced to $\sim 12$ hours.

The clinical impact of this information, while limited, may include more precise predictions of the course of disease and the outcome of therapy. For example, given the preceding discussion, the literature concerning $H$. parainfluenzae endocarditis must be viewed with some caution, since some isolates classified within this species may in actuality have been members of other species or genera (e.g., Actinobacillus). In addition, a delay in species identification may permit the growth of relatively large valvular vegetations associated with the HACEK organisms, which-given the particularly friable nature of these vegetations-may lead to a high frequency of embolization in cases of HACEK endocarditis. Direct amplification of microbial small-subunit rRNA sequences from blood may further reduce such delays in diagnosis. Although the technical expertise required for this kind of approach may not be available in most clinical laboratories, the use of automated DNA-sequencing procedures and simplified protocols may allow regional reference centers to offer small-subunit rRNA-based identification of diverse, fastidious microbial isolates in the near future.

\section{Acknowledgments}

The authors thank Terry L. Lewis for valuable advice and expertise and Harry B. Greenberg and Suzanne M. Matsui for technical support.

\section{References}

1. Kuklinska D, Kilian M. Relative proportions of Haemophilus species in the throat of healthy children and adults. Eur J Clin Microbiol 1984;3:249-52. 
2. Hand WL. Haemophilus species. In: Mandell GL, Douglas RG Jr, Bennett JE, eds. Principles and practice of infectious diseases. 3rd ed. New York: Churchill Livingstone, 1990:1729-33.

3. Black CT, Kupferschmid JP, West KW, Grosfeld JL. Haemophilus parainfluenzae infections in children, with the report of a unique case. Rev Infect Dis 1988;10:342-6.

4. Geraci JE. Wilson WR. Endocarditis due to gram-negative bacteria. Report of 56 cases. Mayo Clin Proc 1982;57:145-8.

5. Kilian M. Haemophilus. In: Balows A, Hausler WJ Jr, Herrmann KL, Isenberg HD, Shadomy HJ, eds. Manual of clinical microbiology. 5th ed. Washington, DC: American Society for Microbiology, 1991:463-70.

6. Relman DA. Loutit JS, Schmidt TM, Falkow S, Tompkins LS. The agent of bacillary angiomatosis-an approach to the identification of uncultured pathogens. N Engl J Med 1990;323:1573-80.

7. Böttger EC, Teske A. Kirschner P, et al. Disseminated "Mycobacterium genavense" infection in patients with AIDS. Lancet 1992;340:76-80.

8. Relman DA. The identification of uncultured microbial pathogens. $\mathbf{J}$ Infect Dis 1993;168:1-8.

9. Frothingham R, Wilson KH. Molecular phylogeny of the Mycobacterium avium complex demonstrates clinically meaningful divisions. $\mathrm{J}$ Infect Dis 1994;169:305-12.

10. Relman DA. Universal bacterial $16 \mathrm{~S}$ rDNA amplification and sequencing. In: Persing DH, Smith TF, Tenover FC, White TJ, eds. Diagnostic molecular microbiology: principles and applications. Washington. DC: American Society for Microbiology, 1993:489-95.

11. Woese CR. Bacterial evolution. Microbiol Rev 1987;51:221-71.

12. Lane DJ, Pace B, Olsen GJ, Stahl DA, Sogin ML, Pace NR. Rapid determination of $16 \mathrm{~S}$ ribosomal RNA sequences for phylogenetic analyses. Proc Natl Acad Sci USA 1985;82:6955-9.

13. Sambrook J, Fritsch EF, Maniatis T. Molecular cloning: a laboratory manual. 2nd ed. Cold Spring Harbor, NY: Cold Spring Harbor Laboratory Press, 1989.

14. Devereux J, Haeberli P. Smithies O. A comprehensive set of sequence analysis programs for the VAX. Nucleic Acids Res 1984;12:387-95.

15. Feng DF, Doolittle RF. Progressive sequence alignment as a prerequisite to correct phylogenetic trees. J Mol Evol 1987;25:351-60.

16. Dewhirst FE, Paster BJ, Olsen I, Fraser GJ. Phylogeny of 54 representative strains of species in the family Pasteurellaceae as determined by comparison of 16S rRNA sequences. J Bacteriol 1992;174:2002-13.

17. Brosius J. Palmer ML, Kennedy PJ, Noller HF. Complete nucleotide sequence of a 16S ribosomal RNA gene from Escherichia coli. Proc Natl Acad Sci USA 1978;75:4801-5.

18. Guttell RR, Weiser B, Woese CR, Noller HF. Comparative anatomy of 16-S-like ribosomal RNA. Prog Nucleic Acid Res Mol Biol 1985;32:155-216.

19. Fox GE, Wisotzkey JD, Jurtshuk P Jr. How close is close: $16 \mathrm{~S}$ rRNA sequence identity may not be sufficient to guarantee species identity. Int J Syst Bacteriol 1992;42:166-70.

20. Russell DS. Fildes P. A case of endocarditis in man associated with Bacillus parainfluenzae, Rivers, 1922. J Pathol Bacteriol 1928:31:651-6.
21. Rivers TM. Influenza-like bacilli; growth of influenza-like bacilli on media containing only an auto-clave-labile substance as an accessory food factor. Bull Johns Hopkins Hosp 1922;33:429-31.

22. Kilian M. A taxonomic study of the genus Haemophilus, with the proposal of a new species. J Gen Microbiol 1976;93:9-62.

23. Janda WM, Bradna JJ, Ruther P. Identification of Neisseria spp., Haemophilus spp., and other fastidious gram-negative bacteria with the MicroScan Haemophilus-Neisseria identification panel. J Clin Microbiol 1989;27:869-73.

24. Barbé G, Babolat M, Boeufgras JM, Monget D, Freney J. Evaluation of API NH, a new 2-hour system for identification of Neisseria and Haemophilus species and Moraxella catarrhalis in a routine clinical laboratory. J Clin Microbiol 1994;32:187-9.

25. Chunn CJ, Jones SR, McCutchan JA, Young EJ, Gilbert DN. Haemophilus parainfluenzae infective endocarditis. Medicine (Baltimore) 1977;56:99-113.

26. Geraci JE, Wilkowske CJ, Wilson WR, Washington JA II. Haemophilus endocarditis. Report of 14 patients. Mayo Clin Proc 1977:52:209-15.

27. Lynn DJ, Kane JG, Parker RH. Haemophilus parainfluenzae and influenzae endocarditis: review of forty cases. Medicine (Baltimore) 1977;56:115-28.

28. Ellner JJ, Rosenthal MS, Lerner PI, McHenry MC. Infective endocarditis caused by slow-growing, fastidious, gram-negative bacteria. Medicine (Baltimore) 1979;58:145-58.

29. Jemsek JG, Greenberg SB, Gentry LO, Welton DE, Mattox KL. Haemophilus parainfluenzae endocarditis. Two cases and review of the literature in the past decade. Am J Med 1979;66:51-7.

30. Raucher B, Dobkin J, Mandel L, Edberg S, Levi M, Miller M. Occult polymicrobial endocarditis with Haemophilus parainfluenzae in intravenous drug abusers. Am J Med 1989;86:169-72.

31. Gordon AM, Love WC. Endocarditis due to Haemophilus parainfluenzae. J Med Microbiol 1970;3:550-4.

32. Stahl DA, Urbance JW. The division between fast- and slow-growing species corresponds to natural relationships among the mycobacteria. J Bacteriol 1990;172:116-24.

33. Pitulle C, Dorsch M, Kazda J, Wolters J, Stackebrandt E. Phylogeny of rapidly growing members of the genus Mycobacterium. Int J Syst Bacteriol 1992:42:337-43.

34. Dewhirst FE, Paster BJ, Olsen I, Fraser GJ. Phylogeny of the Pasteurellaceae as determined by comparison of $16 \mathrm{~S}$ ribosomal ribonucleic acid sequences. Int $\mathbf{J}$ Med Microbiol Virol Parasitol Infect Dis 1993:279:35-44.

35. Carbon P, Ehresmann C, Ehresmann B, Ebel JP. The complete nucleotide sequence of the ribosomal 16-S RNA from Escherichia coli. Experimental details and cistron heterogeneities. Eur $\mathbf{J}$ Biochem 1979;100:399-410.

36. Ruano G, Kidd KK. Coupled amplification and sequencing of genomic DNA. Proc Natl Acad Sci USA 1991;88:2815-9.

37. Tracy TE, Mulcahy LS. A simple method for direct automated sequencing of PCR fragments. Biotechniques 1991;11:68-75. 